\section{Clarifying the Barriers to Optimal Healthcare for Persons with Inflammatory Arthritis}

\section{To the Editor:}

Our research group investigated reasons for provision of suboptimal healthcare for persons with rheumatoid arthritis (RA) within the McGill University health network. In light of the recent article by Graydon and Thompson ${ }^{1}$, and the accompanying editorial by Harrington ${ }^{2}$, we report some of our preliminary findings.

Recent work by Feldman, et $a l^{3}$ suggested low rates of rheumatology referral for persons with suspected RA in Quebec, so we began with a series of focus group discussions to investigate reasons for this phenomenon. We conducted separate focus groups for major stakeholders (patients, family physicians, rheumatologists, allied healthcare providers, and administrative healthcare decision-makers). We had 3 focus groups for family physicians, with a total of 13 participants ( 9 men, 4 women).

Across the stakeholder groups, commonly emerging themes included the value of communication (between physicians and patients, and between healthcare providers), education (of patients, healthcare providers, and the general community), and adequate resources (including healthcare provider personnel). Interestingly, family physicians themselves did in fact identify the benefits of early treatment in RA; given the limited experience of family physicians with disease-modifying agents, it was felt that a rheumatologist should play the primary role. On the other hand, the family physicians did indicate that diagnostic criteria for RA were not clear to them, and voiced the desire for more education in this regard.

The family physicians also indicated that serious barriers existed to the prompt referral of a patient with suspected RA. For example, both family physicians and the patient groups mentioned hesitation or even resistance on the part of the patient to seek medical care and/or follow-through with a consultation to a specialist. In particular, in rural areas, it was suggested that there was a tendency for a patient to dislike travelling distances for specialty care. Lower socioeconomic status of the patient was also mentioned as a factor, since these patients had fewer resources, including education, that would assist them in efforts to seek health care, and follow through with recommendations. This corresponds to the findings of Feldman, $e a^{3}$, who noted lower rheumatology referrals for patients who lived in rural areas and for those of lower socioeconomic status.

On another level, the family physicians were very concerned about rheumatology as a "limited resource." They suggested a tendency to refer only the most urgent cases promptly, since they felt that otherwise they were contributing to the burden carried by rheumatologists. However, even when the family physicians were anxious to ensure that a patient was seen promptly by a rheumatologist, there were impediments. One example was the difficulty in being able to reach a rheumatologist by telephone to discuss a given case.

We feel that our investigations shed additional light on the work of Graydon and Thompson. The authors point out that "the mean duration of symptoms in these urgent patients prior to referral was more than 7 months," and imply that this may be due to a "deficiency at the primary care level" (as well as lack of rheumatology manpower). This leaves out one important factor - the patient - who may contribute to the delay. Indeed, the patient has been identified as the primary rate-limiting step in recent studies ${ }^{4,5}$

Thus, although some may feel that simple clinical criteria for identifying patients with early inflammatory arthritis are ignored by family physicians, it may be a question of lack of education. Based on our focus group discussion, family physicians are eager to improve practice, and recommendations to "discard the expectation of improving referring physician performance through education" seems rather harsh and self-defeating. We acknowledge that improving quality of care requires several approaches, including redesigning processes to resolve system-level problems. As recent authors have emphasized, these efforts could include clear clinical guidelines (properly endorsed and disseminated, with the input of family physicians), medical education, and other quality improvement efforts ${ }^{6}$. Very similar themes were identified in the 2006 Standards in Arthritis Prevention and Care, which were developed by the Alliance for the Canadian Arthritis Program ${ }^{7}$. Of note, these standards carry the same messages as the 2004 Standards of Care for People with Inflammatory Arthritis endorsed by the Arthritis and Musculoskeletal Alliance in the United Kingdom ${ }^{8}$.

As was emphasized in the joint US and Canadian conference on Co-Management Models of Care for Early Diagnosis of Inflammatory Arthritis ${ }^{9}$, the early diagnosis and treatment of people with inflammatory arthritis will require new models of integrated care, with the input not only of primary care practitioners and rheumatologists but ideally, of patient advocacy groups and allied health professionals.

SASHA BERNATSKY, MD, PhD, McGill University; DEBBIE EHRMANN FELDMAN, PhD, Université de Montréal; MARTIN DAWES, MBBS, PhD, McGill University; JEAN LEGARE, Honorary Doctorate, Alliance for the Canadian Arthritis Program; CHRISTOPHER MILL, McGill University; MICHEL ZUMMER, MD, FRCPC, Hôpital Maisonneuve-Rosemont; JENNIFER LEE, BSc, McGill University, Montreal, Quebec, Canada. Address reprint requests to Dr. S. Bernatsky, Division of Clinical Epidemiology,

Research Institute of the McGill University Health Centre, 687 Pine Avenue West, V-Building, Montreal, Quebec H3A 1A1, Canada. E-mail: sasha.bernatsky@mail.mcgill.ca

\section{REFERENCES}

1. Graydon SL, Thompson AE. Triage of referrals to an outpatient rheumatology clinic: analysis of referral information and triage. J Rheumatol 2008;35:1378-83.

2. Harrington T. Improving access to rheumatology care: a continuing challenge [editorial]. J Rheumatol 2008;35:1233-4.

3. Feldman DE, Bernatsky S, Haggerty J, et al. Delay in consultation with specialists for persons with suspected new-onset rheumatoid arthritis: A population-based study. Arthritis Rheum 2007:57:1419-25.

4. Kumar K, Daley E, Carruthers DM, et al. Delay in presentation to primary care physicians is the main reason why patients with rheumatoid arthritis are seen late by rheumatologists. Rheumatology Oxford 2007;46:1438-40.

5. Sandhu RS, Treharne GJ, Justice EA, et al. Comment on: Delay in presentation to primary care physicians is the main reason why patients with rheumatoid arthritis are seen late by rheumatologists. Rheumatology Oxford 2008;47:559-60; author reply 560.

6. Suter LG, Fraenkel L, Holmboe ES. What factors account for referral delays for patients with suspected rheumatoid arthritis? Arthritis Rheum 2006;55:300-5.

7. Alliance for the Canadian Arthritis Program. Report: Summit on standards for arthritis prevention and care; November 1-2, 2005, Ottawa, Canada. Arthritis isn't a big deal, until you get it. February 2006. [Internet. Cited Dec 22 2008.] Available from: http://www.arthritisalliance.ca/docs/SAPC\%20Full\%20Report\%202 0060331\%20en.pdf

8. Arthritis and Musculoskeletal Alliance. Standards of care for people with inflammatory arthritis. November 2004. [Internet. Cited Dec 22 2008]. Available from: http://www.arma.uk.net/pdfs/ia06.pdf

9. White M, White P, Buckley L. American and Canadian co-management models of care for early diagnosis of inflammatory arthritis; October 19-20, 2007, Bethesda, MD. The Arthritis Foundation. [Internet. Cited Dec 22, 2008]. Available from: http://www.cirpd.org/arthritis/report/cfm/

J Rheumatol 2009;36:4; doi:10.3899/jrheum.080833 